\title{
Impact of chronic obstructive pulmonary disease on postoperative recurrence in patients with resected non-small-cell lung cancer
}

This article was published in the following Dove Press journal:

International Journal of COPD

29 December 2015

Number of times this article has been viewed

\author{
Guangliang Qiang \\ Chaoyang Liang \\ Fei Xiao \\ Qiduo Yu \\ Huanshun Wen \\ Zhiyi Song \\ Yanchu Tian \\ Bin Shi \\ Yongqing Guo \\ Deruo Liu
}

Department of Thoracic Surgery, China-Japan Friendship Hospital, Beijing, People's Republic of China

Correspondence: Deruo Liu Department of Thoracic Surgery, China-Japan Friendship Hospital,

Yinghua East Road No 2, Chaoyang

District, Beijing 100029, People's

Republic of China

$\mathrm{Tel}+861084206186$

Fax +861084206200

Email deruoliu@vip.sina.com
Purpose: This study aimed to determine whether the severity of chronic obstructive pulmonary disease (COPD) affects recurrence-free survival in non-small-cell lung cancer (NSCLC) patients after surgical resection.

Patients and methods: A retrospective study was performed on 421 consecutive patients who had undergone lobectomy for NSCLC from January 2008 to June 2011. Classification of COPD severity was based on guidelines of the Global Initiative for Chronic Obstructive Lung Disease (GOLD). Characteristics among the three subgroups were compared and recurrencefree survivals were analyzed.

Results: A total of 172 patients were diagnosed with COPD (124 as GOLD-1, 46 as GOLD-2, and two as GOLD-3). The frequencies of recurrence were significantly higher in patients with higher COPD grades $(P<0.001)$. Recurrence-free survival at 5 years was $78.1 \%, 70.4 \%$, and $46.4 \%$ in non-COPD, mild COPD, and moderate/severe COPD groups, respectively $(P<0.001)$. By univariate analysis, the age, sex, smoking history, COPD severity, tumor size, histology, and pathological stage were associated with recurrence-free survival. Multivariate analysis showed that older age, male, moderate/severe COPD, and advanced stage were independent risk factors associated with recurrence-free survival.

Conclusion: NSCLC patients with COPD are at high risk for postoperative recurrence, and moderate/severe COPD is an independent unfavorable prognostic factor.

Keywords: lung neoplasms, surgery, pulmonary function test, prognosis

\section{Introduction}

Lung cancer and chronic obstructive pulmonary disease (COPD) are both common diseases worldwide. Lung cancer is the leading cause of cancer related deaths with a 5-year survival rate of about $16 \%{ }^{1}$ Meanwhile, COPD is the fourth leading cause of death globally, which is expected to become the third by $2020 .^{2}$ Epidemiological survey discovers that the presence of COPD increases the risk of lung cancer by 4.5 -fold. ${ }^{3,4}$ Moreover, $\sim 40 \%-70 \%$ of lung cancer patients complicate with COPD. ${ }^{5}$ Patients undergoing pulmonary resection for lung cancer with COPD are thought to be at increased risk of short-term complications and surgery-related death. Furthermore, Zhai et $\mathrm{al}^{6}$ found that patients with COPD had increased risk of worse overall survival and progression-free survival. For patients with stage I non-small-cell lung cancer (NSCLC), the decline in overall survival after lobectomy was associated with lower pulmonary function. ${ }^{7}$ However, whether the severity of COPD affects recurrence-free survival (RFS) after complete resection for NSCLC remains unclear. The purpose of this study was to investigate the impact of COPD on postoperative recurrence in patients with resectable NSCLC. 


\section{Material and methods}

\section{Patients}

We performed a retrospective review of consecutive patients with NSCLC who underwent lobectomies with systematic mediastinal lymph node dissection at our hospital from January 2008 to June 2011. This study was approved by the Institutional Review Board of the China-Japan Friendship Hospital in accordance with the Declaration of Helsinki. All patients signed written informed consent prior to surgery. Histological type and pathological stage for each patient were determined according to 2004 World Health Organization (WHO) Classification of Lung Tumors and the 7th edition of TNM classification for lung cancer proposed by the International Association for the Study of Lung Cancer (IASLC). ${ }^{8}$ The inclusion criteria were: 1) primary NSCLC confirmed pathologically; 2) underwent standard pulmonary function test a week prior to surgery; 3) lobectomy and systematic lymph node dissection were performed without either microscopic or macroscopic residual tumor. The exclusion criteria were: 1) presented with simultaneous or sequential second primary cancers; 2) had neoadjuvant therapy (chemotherapy and/or radiation therapy);3) the presence of pneumonia, atelectasis, pulmonary interstitial fibrosis, and other diseases that might affect pulmonary function before surgery; 4) incomplete resection with macroscopic or microscopic residual disease; 5) died of complications within 1 month after surgery.

\section{Evaluation of pulmonary function}

Pulmonary function was measured by a computerized spirometer (Master Screen Body, Jaeger, Würzburg, Germany) according to the standardization criteria of the American Thoracic Society. ${ }^{9}$ Measurements included forced vital capacity (FVC), percentage of FVC (FVC\%), forced expiratory volume in 1 second $\left(\mathrm{FEV}_{1}\right)$, percentage of $\mathrm{FEV}_{1}$ $\left(\mathrm{FEV}_{1} \%\right.$ ), and $\mathrm{FEV}_{1} / \mathrm{FVC}$ ratio.

The diagnosis and severity was determined by spirometric criteria of the Global Initiative for Chronic Obstructive Lung Disease (GOLD). ${ }^{10} \mathrm{FEV}_{1} / \mathrm{FVC}<70 \%$ was diagnosed as COPD. The severity of COPD was graded by the degree of decrease in $\mathrm{FEV}_{1}: 1$ ) $\mathrm{FEV}_{1} \geq 80 \%$ predicted, mild (GOLD-1); 2) $50 \% \leq \mathrm{FEV}_{1}<80 \%$ predicted, moderate (GOLD-2); $30 \% \leq \mathrm{FEV}_{1}<50 \%$ predicted, severe (GOLD-3); and $\mathrm{FEV}_{1}<30 \%$ predicted, extremely severe (GOLD-4).

\section{Follow-up}

Patients were initially followed up at 1 month after resection by the thoracic surgeon, then at 3-month intervals for the first 2 years, and thereafter every 6-12 months.
The postoperative evaluations included clinical assessments, tumor marker measurement, chest computed tomography (CT), abdominal CT or ultrasonography, CT or magnetic resonance imaging (MRI) of the brain and bone scintigraphy. All of the patients were followed. The median follow-up period was 50 months (range: 10-83 months). Recurrences were diagnosed by physical examination and diagnostic imaging. Second primary lung cancer was differentiated from recurrence according to the criteria proposed previously. ${ }^{11}$ Pathological confirmation of recurrence was made when clinically feasible. RFS was defined as the duration from the date of surgery to the most recent follow-up contact or to the date of recurrence or death.

\section{Statistical analysis}

Categorical variables were expressed as counts and percentages, and continuous variables were expressed as mean \pm standard deviation. One-way analysis of variance was performed to compare continuous variables; the $\chi^{2}$ (chi-square) test or Fisher's exact test as appropriate was applied to compare categorical variables among groups. Correlations between variables were determined using the Spearman's rank test. Survival curves were generated by Kaplan-Meier method and the statistical significance of differences between groups were assessed by log-rank test. Multivariate analyses were performed by means of a Cox proportional hazards model. The software package SPSS version 20.0 (IBM Corp., Armonk, NY, USA) was used for all statistical analyses. Statistical significance was considered at $P<0.05$.

\section{Results}

The clinicopathological features of the patients are listed in Table 1. A total of 421 consecutive cases were included in this study, including 260 males and 161 females. The median age was 67 years (range: $32-84$ years). Of these patients, 273 had smoking history. Pathological TNM stages were stage I in 356 patients, stage II in 36 patients, and stage IIIA in 29 patients. During the follow-up period, recurrence was observed in 83 patients, 32 cases had local-regional recurrences, distant metastases were identified in 22 cases, both local-regional recurrence and distant metastases occurred in nine cases. The most common site of local-regional recurrence was the lung in 24 cases, followed by mediastinal lymph node in 16 cases, pleura in eight cases, and bronchial stump in four cases. The brain was the most common site of distant metastases (ten cases), followed by the bone (eight cases), the liver (two cases), and the adrenals (one case). A total of 172 patients were diagnosed with COPD, including 124 mild cases (GOLD-1), 
Table I Patient characteristics and the severity of COPD

\begin{tabular}{|c|c|c|c|c|}
\hline Characteristics & $\begin{array}{l}\text { Non-COPD, } \\
n=249 \text { (\%) }\end{array}$ & $\begin{array}{l}\text { Mild COPD, } \\
n=124(\%)\end{array}$ & $\begin{array}{l}\text { Moderate/severe } \\
\text { COPD, } n=48 \text { (\%) }\end{array}$ & $P$-value \\
\hline Age (years) & & & & $<0.001$ \\
\hline$<65$ & I I 8 (47.4) & $24(19.4)$ & $13(27.1)$ & \\
\hline$\geq 65$ & $|3|$ (52.6) & $100(80.6)$ & 35 (72.9) & \\
\hline Sex & & & & $<0.001$ \\
\hline Female & $117(47.0)$ & $35(28.2)$ & $9(18.8)$ & \\
\hline Male & I $32(53.0)$ & $89(71.8)$ & $39(81.3)$ & \\
\hline Smoking history & & & & $<0.001$ \\
\hline No & III (44.6) & $33(26.6)$ & $4(8.3)$ & \\
\hline Yes & $138(55.4)$ & 91 (73.4) & $44(91.7)$ & \\
\hline Tumor size $(\mathrm{cm})$ & & & & 0.405 \\
\hline$\leq 3$ & $214(85.9)$ & $100(80.6)$ & $4 \mid(85.4)$ & \\
\hline$>3$ & $35(14.1)$ & $24(19.4)$ & $7(14.6)$ & \\
\hline Tumor location & & & & 0.289 \\
\hline Left upper lobe & $65(26.1)$ & $4 I(33 . I)$ & $8(16.7)$ & \\
\hline Left lower lobe & 37 (14.9) & $16(12.9)$ & $8(16.7)$ & \\
\hline Right upper lobe & $83(33.3)$ & $35(28.2)$ & $14(29.2)$ & \\
\hline Right middle lobe & $18(7.2)$ & $9(7.3)$ & $2(4.2)$ & \\
\hline Right lower lobe & $46(18.5)$ & $23(18.5)$ & $16(33.3)$ & \\
\hline Procedure & & & & 0.385 \\
\hline VATS & I33 (53.4) & $73(58.9)$ & $23(47.9)$ & \\
\hline Open & $116(46.6)$ & $5 I(4 I . I)$ & $25(52.1)$ & \\
\hline Histology & & & & $<0.001$ \\
\hline Ad & $213(85.5)$ & $78(62.9)$ & $27(56.3)$ & \\
\hline Non-Ad & $36(14.5)$ & $46(37.1)$ & $21(43.7)$ & \\
\hline Pathological stage & & & & 0.002 \\
\hline 1 & $220(88.4)$ & $103(83.1)$ & $33(68.8)$ & \\
\hline II & $14(5.6)$ & $16(12.9)$ & $6(12.5)$ & \\
\hline III & $15(6.0)$ & $5(4.0)$ & $9(18.8)$ & \\
\hline Adjuvant chemotherapy & & & & 0.773 \\
\hline No & $220(88.4)$ & $107(86.3)$ & $4 \mathrm{I}(85.4)$ & \\
\hline Yes & $29(11.6)$ & $17(13.7)$ & $7(14.6)$ & \\
\hline Recurrence & & & & $<0.001$ \\
\hline No & $211(84.7)$ & $98(79.0)$ & $29(60.4)$ & \\
\hline Yes & $38(I 5.3)$ & $26(21.0)$ & $19(39.6)$ & \\
\hline Recurrence style & & & & 0.648 \\
\hline Local-regional & $21(55.3)$ & $17(65.4)$ & 14 (73.7) & \\
\hline Distant & $12(31.6)$ & $7(26.9)$ & $3(15.8)$ & \\
\hline Both & $5(13.2)$ & $2(7.7)$ & $2(10.5)$ & \\
\hline
\end{tabular}

Abbreviations: Ad, adenocarcinoma; COPD, chronic obstructive pulmonary disease; VATS, video-assisted thoracoscopic surgery.

46 moderate cases (GOLD-2), and two severe cases (GOLD-3). The whole study population was stratified into non-COPD, mild COPD, and moderate/severe COPD groups. The elevated severity of COPD categories tended to include male, older individuals with a history of smoking, advanced pathological stage and non-adenocarcinoma histology. The postoperative recurrent rate was higher as the severity of COPD increased. The three groups were similar in terms of tumor size, bearing lobe, and adjuvant therapy. Preoperative pulmonary function of patients is summarized in Table 2. As the severity of COPD increased, $\mathrm{FVC}, \mathrm{FVC} \%, \mathrm{FEV}_{1}, \mathrm{FEV}_{1} \%$, and $\mathrm{FEV}_{1} / \mathrm{FVC} \%$ all decreased significantly $(P<0.05$, Table 2$)$.
The 1-, 3-, and 5-year RFS was 96.7\%, 85.2\%, and 72.7\%, respectively (Figure 1). The 5-year RFS in NSCLC patients with COPD was $64.0 \%$, significantly lower than that of non-COPD patients $(78.1 \%)(P=0.002)$. The Kaplan-Meier survival curves indicated that COPD was associated with decreased RFS in either all patients or pathological stage I patients ( $P=0.002$ and $P=0.003$, respectively) (Figure 2 ). Subgroup analysis indicated that the 5-year RFS was $70.4 \%$ for mild COPD group, which was comparable with that of non-COPD group $(P=0.115)$. However, the 5-year RFS of moderate/severe COPD group was $46.4 \%$, significantly lower than that of non-COPD group $(P<0.001)$ and mild COPD 
Table 2 Comparison of pulmonary function among groups with different severity of COPD

\begin{tabular}{|c|c|c|c|c|}
\hline $\begin{array}{l}\text { Pulmonary } \\
\text { function tests }\end{array}$ & $\begin{array}{l}\text { Non-COPD } \\
(n=249)\end{array}$ & $\begin{array}{l}\text { Mild COPD } \\
(n=\mid 24)\end{array}$ & $\begin{array}{l}\text { Moderate/severe } \\
\text { COPD }(n=48)\end{array}$ & $P$-value \\
\hline FVC (L) & $3.30 \pm 0.84$ & $3.08 \pm 0.74$ & $3.02 \pm 0.8 I$ & 0.022 \\
\hline \%FVC (\%) & $113.35 \pm 15.97$ & $107.19 \pm 17.38$ & $97.14 \pm 17.46$ & $<0.001$ \\
\hline $\mathrm{FEV}_{1}(\mathrm{~L})$ & $2.21 \pm 0.77$ & $1.90 \pm 0.72$ & $1.58 \pm 0.53$ & $<0.001$ \\
\hline \%FEV $(\%)$ & $109.61 \pm 16.68$ & $82.93 \pm 18.50$ & $69.93 \pm 9.44$ & 0.045 \\
\hline FEV,/FVC (\%) & $78.04 \pm 6.32$ & $63.39 \pm 5.43$ & $54.4 I \pm 9.20$ & $<0.001$ \\
\hline
\end{tabular}

Note: The continuous variables are presented as mean \pm SD.

Abbreviations: COPD, chronic obstructive pulmonary disease; $\mathrm{FEV}_{1}$, forced expiratory volume in I second; FVC, forced vital capacity.

group $(P=0.001)$ (Figure 3A). In pathological stage I patients, the 5 -year RFS was $83.1 \%$ for non-COPD group, $76.8 \%$ for mild COPD group $(P=0.100)$. However, the 5 -year RFS of moderate/severe COPD group was $54.1 \%$, significantly lower than that of non-COPD group $(P<0.001)$ and mild COPD group $(P=0.003)$ (Figure $3 \mathrm{~B})$. Univariate analysis revealed that the age, sex, smoking history, tumor size, histological type, and pathological staging were all significant predictors of RFS (Table 3). These variables identified by univariate analysis were included in Cox proportional hazards model to verify independent prognostic factors. Multivariate analysis demonstrated that moderate/severe COPD was an independent prognostic factor for RFS (hazard ratio $(\mathrm{HR})=1.718$, 95\% confidence interval (CI): 1.086-2.919), along with the age, sex, and pathological stage (Table 4).

\section{Discussion}

The aim of this study was to examine the correlation between COPD and postoperative recurrence in patients with resected

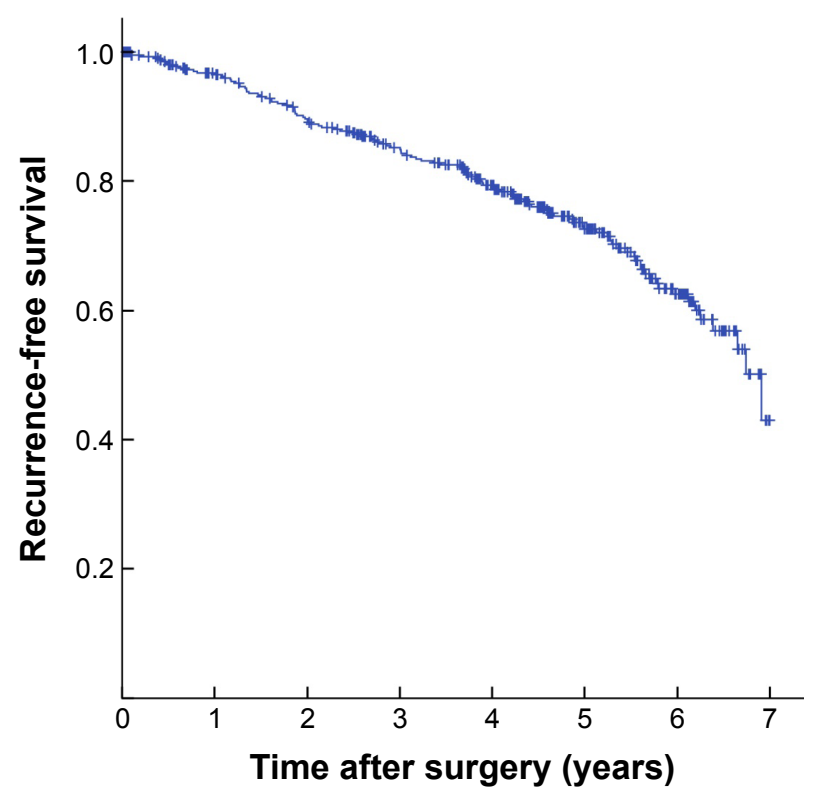

Figure I Kaplan-Meier survival curves of recurrence-free survival for the whole study population.
NSCLC. In the present study, we found that coexisting COPD was associated with worse RFS. Furthermore, our results indicate that moderate/severe COPD is an independent risk factor for recurrence, while mild COPD does not carry a similar risk.

Both COPD and lung cancer are common fatal diseases. They share some risk factors in common, including smoking, environmental exposure, and genetic predisposition. COPD also plays an important role in the pathogenesis and progression of lung cancer. ${ }^{12}$ Thus, there is a close relationship between them and the coexistence is frequent. ${ }^{13,14}$ The risk of lung cancer in patients with COPD is fivefold greater compared with smokers without COPD. ${ }^{4}$ In COPD cohort studies, the incidence of lung cancer was 16.7 cases per 1,000 person-years, and $20 \%-30 \%$ of COPD patients died of lung cancer. ${ }^{4,5}$ Moreover, the risk of lung cancer increased in proportion to the severity of COPD. ${ }^{15,16}$ On the other hand, the prevalence of COPD diagnosed by spirometry in newly diagnosed lung cancer patients was found to be $40 \%-70 \% .5,17$ In our study, $40.8 \%$ of patients with NSCLC had coexisting COPD, consistent with previous reports. As adequate pulmonary reserve was necessary for lobectomy, the majority of COPD patients in our cohort were mild to moderate; only two patients were severe. Our results confirmed that $\mathrm{FEV}_{1} \%$ was positively correlated with other pulmonary function indicators, including $\mathrm{FVC}, \mathrm{FVC} \%, \mathrm{FEV}_{1}$, and $\mathrm{FEV}_{1} / \mathrm{FVC}$ levels. The stratification system based on $\mathrm{FEV}_{1} \%$ provides an accurate assessment of pulmonary function status for COPD patients. We found that increased severity of COPD was more frequent in males, elders, smokers, and non-adenocarcinoma patients. This might be explained by the following: cigarette exposure-induced inflammatory response contributes to the development of COPD and squamous cell lung carcinoma, the prevalence of smokers is more frequent in the male population as well as non-adenocarcinoma patients, and the age reflects the sum of cumulative exposures throughout life.

The correlation of COPD severity with the incidence of cardiopulmonary complications after surgery has been 

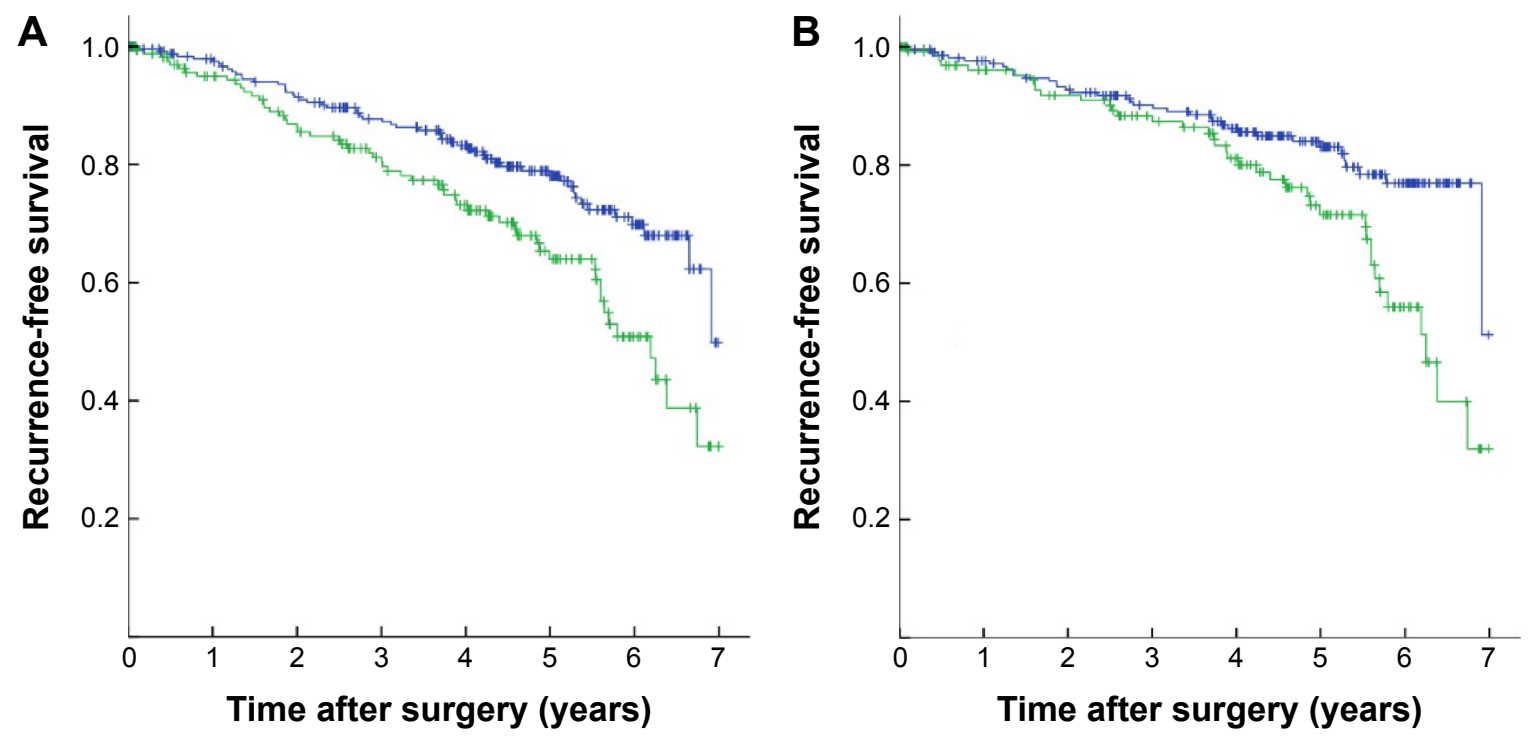

$\neg$ Non-COPD $\neg$ With COPD

Figure 2 Kaplan-Meier curves for recurrence-free survival stratified by COPD.

Notes: (A) Kaplan-Meier survival curves for patients with NSCLC according to the presence of COPD ( $P=0.002)$. (B) Kaplan-Meier survival curves for patients with pathological stage I NSCLC according to the presence of COPD $(P=0.003)$.

Abbreviations: COPD, chronic obstructive pulmonary disease; NSCLC, non-small-cell lung cancer.

well established in previous studies. However, the effect of COPD on the survival after resection of lung cancer is still uncertain. Several studies reported that NSCLC with COPD has a poor prognosis. Gullon et al ${ }^{18}$ found that pulmonary emphysema was an adverse prognostic factor in NSCLC.
Kiri et $\mathrm{al}^{19}$ reported that the 3-year survival of lung cancer patients with COPD was almost half that of patients without COPD. Sekine et $\mathrm{al}^{20}$ showed that COPD was a risk factor for predicting survival after surgical resection for stage IA lung cancer. However, Arca et $\mathrm{al}^{21}$ reported that the survival
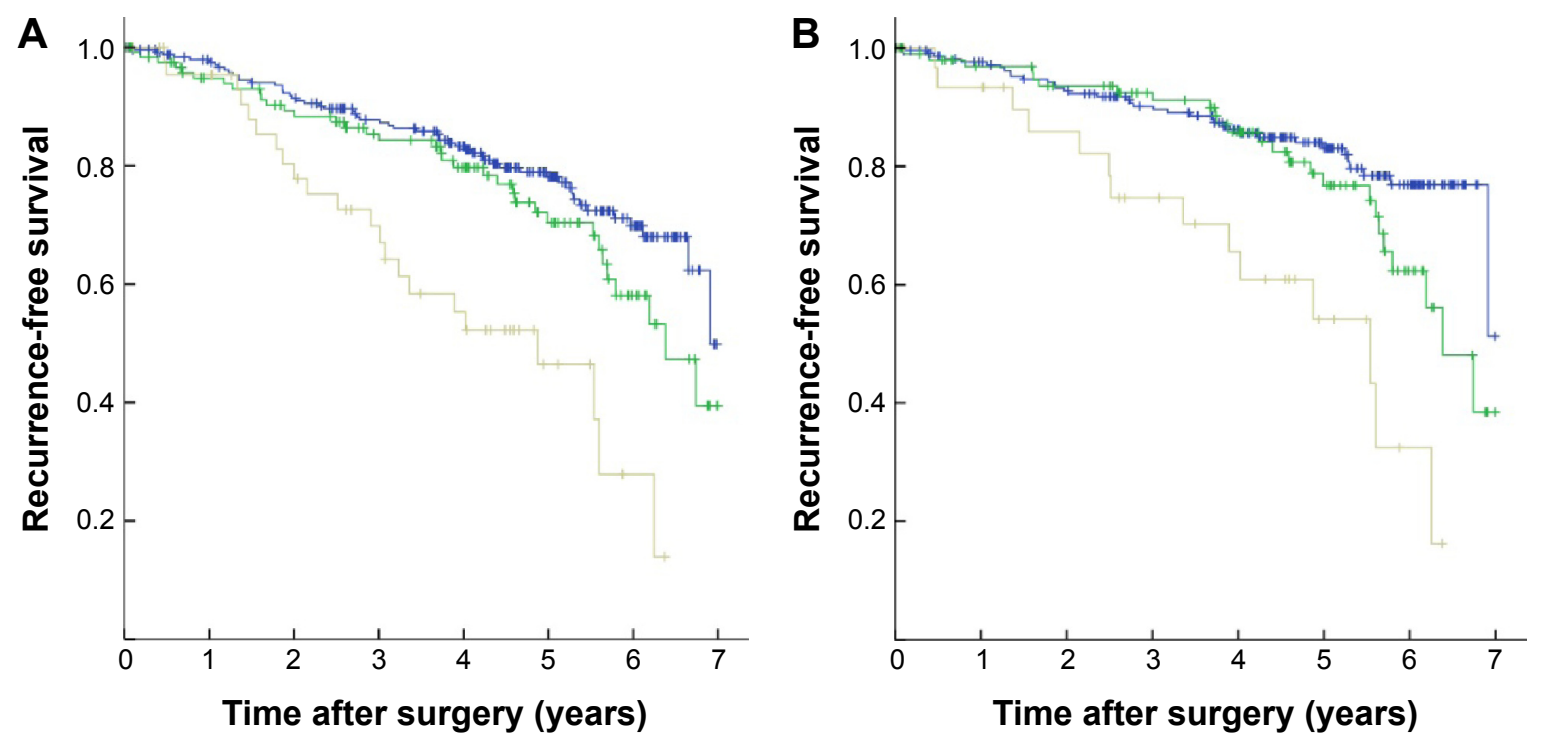

$\neg$ Non-COPD $\neg$ Mild COPD $\neg$ Moderate/severe COPD

Figure 3 Kaplan-Meier curves for recurrence-free survival stratified by COPD severity.

Notes: (A) Kaplan-Meier survival curves for patients with NSCLC according to COPD severity $(P<0.00 \mathrm{I})$. (B) Kaplan-Meier survival curves for patients with pathological stage I NSCLC according to COPD severity $(P<0.001)$.

Abbreviations: COPD, chronic obstructive pulmonary disease; NSCLC, non-small-cell lung cancer. 
Table 3 Univariate analysis of risk factors associated with recurrence-free survival

\begin{tabular}{|c|c|c|c|}
\hline Characteristics & $\begin{array}{l}\text { Cases } \\
(n=42 I)\end{array}$ & $\begin{array}{l}\text { 5-year RFS } \\
\text { rate }(\%)\end{array}$ & $P$-value \\
\hline Age (years) & & & 0.001 \\
\hline$<65$ & 155 & 82.7 & \\
\hline$\geq 65$ & 266 & 65.4 & \\
\hline Sex & & & $<0.001$ \\
\hline Female & 161 & 85.9 & \\
\hline Male & 260 & 63.8 & \\
\hline Smoking history & & & $<0.001$ \\
\hline No & 148 & 82.8 & \\
\hline Yes & 273 & 66.7 & \\
\hline COPD & & & $<0.001$ \\
\hline Non & 249 & 78.1 & \\
\hline Mild & 124 & 70.4 & \\
\hline Moderate/severe & 48 & 46.4 & \\
\hline Tumor size $(\mathrm{cm})$ & & & 0.002 \\
\hline$\leq 3$ & 355 & 74.8 & \\
\hline$>3$ & 66 & 58.5 & \\
\hline Tumor location & & & 0.372 \\
\hline Left upper lobe & 114 & 69.6 & \\
\hline Left lower lobe & 61 & 68.5 & \\
\hline Right upper lobe & 132 & 78.4 & \\
\hline Right middle lobe & 29 & 79.2 & \\
\hline Right lower lobe & 85 & 68.2 & \\
\hline Procedure & & & 0.145 \\
\hline VATS & 229 & 75.2 & \\
\hline Open & 192 & 67.3 & \\
\hline Histology & & & $<0.001$ \\
\hline Ad & 318 & 77.3 & \\
\hline Non-Ad & 103 & 56.9 & \\
\hline Pathological stage & & & $<0.001$ \\
\hline 1 & 356 & 78.4 & \\
\hline II & 36 & 54.3 & \\
\hline III & 29 & 43.2 & \\
\hline Adjuvant chemotherapy & & & 0.351 \\
\hline No & 368 & 74.4 & \\
\hline Yes & 53 & 68.3 & \\
\hline
\end{tabular}

Abbreviations: Ad, adenocarcinoma; COPD, chronic obstructive pulmonary disease; RFS, recurrence-free survival; VATS, video-assisted thoracoscopic surgery.

Table 4 Multivariate analysis of risk factors for recurrence-free survival with proportional hazard model

\begin{tabular}{|c|c|c|c|c|}
\hline Variables & $\chi^{2}$ & $\begin{array}{l}\text { Hazard } \\
\text { ratio }\end{array}$ & $95 \% \mathrm{Cl}$ & $P$-value \\
\hline Age $(\geq 65$ vs $<65)$ & 8.496 & 1.878 & $1.229-2.868$ & 0.004 \\
\hline Sex (male vs female) & 6.394 & 2.055 & I.176-3.593 & 0.011 \\
\hline Smoking history (yes vs no) & 0.799 & 1.296 & $0.734-2.290$ & 0.371 \\
\hline $\begin{array}{l}\text { Moderate/severe COPD } \\
\text { (yes vs no) }\end{array}$ & 5.234 & 1.718 & $1.086-2.919$ & 0.022 \\
\hline Tumor size $(>3 \mathrm{~cm}$ vs $\leq 3 \mathrm{~cm})$ & 1.333 & 1.357 & $0.808-2.277$ & 0.248 \\
\hline Histology (non-Ad vs Ad) & 1.334 & 1.290 & $0.837-1.987$ & 0.248 \\
\hline Pathological stage (II/III vs I) & 29.509 & 3.363 & $2.171-5.210$ & $<0.001$ \\
\hline
\end{tabular}

Abbreviations: $\mathrm{Ad}$, adenocarcinoma; $\mathrm{Cl}$, confidence interval; COPD, chronic obstructive pulmonary disease. of lung cancer patients with COPD was longer. Another two studies did not find any significant correlation between COPD and prognosis in patients with NSCLC. ${ }^{22,23}$ The discrepant findings may be due to the differences in ethnicity, inclusion criteria, sample size, and treatment method. To minimize the effect of confounders, we only included complete lobar resection other than sublobar resection, pneumonectomy or incomplete resection. Our findings indicate that poor oncologic outcome in patients with COPD is due to a higher risk of tumor recurrence. The RFS of NSCLC with COPD was significantly worse than that without COPD. Subgroup analysis revealed that moderate/severe COPD was the main cause while mild COPD did not have a significant impact on RFS.

Several possible mechanisms may explain this association. The tumor cells originating from the lung parenchyma with excessive inflammatory responses tend to be more aggressive. ${ }^{3}$ Chronic inflammation promotes tumor proliferation, angiogenesis, and metastasis through the production of inflammatory mediators, including chemokines, cytokines, and secretion of C-reactive protein (CRP). ${ }^{24}$ It has been reported that a variety of inflammatory mediators, such as tumor necrosis factor- $\alpha$ (TNF- $\alpha$ ), interleukin-1 (IL-1), and IL-6, promote the survival of circulating tumor cells and epithelial-mesenchymal transition, which is important for the invasion and metastasis of NSCLC. ${ }^{25,26}$ Genetic mutation and abnormal gene expression may also accelerate cancer recurrence and metastasis in patients with COPD. ${ }^{14}$ The activation of signal transduction pathways including nuclear-factor kappa B (NF- $\mathrm{BB})$ and signal transducer and activator of transcription 3 (STAT3) enhance invasion and metastasis of tumor cells. There is some potential overlap in regions linked to COPD and lung cancer on chromosomes $6 \mathrm{q}$ and $12 \mathrm{p} .{ }^{27}$ Therefore, further studies are needed to elucidate the potential underlying mechanisms.

\section{Conclusion}

We found that moderate/severe COPD was an independent unfavorable prognostic factor after complete resection for NSCLC. The severity of COPD based on $\mathrm{FEV}_{1}$ can be a useful tool to identify patients at high risk for recurrence. Our results suggest that comprehensive therapeutic strategies are required to improve RFS of resectable lung cancer with moderate to severe COPD.

\section{Author contributions}

All authors contributed toward data analysis, drafting and critically revising the paper, gave final approval of the version 
to be published, and agree to be accountable for all aspects of the work.

\section{Disclosure}

The authors report no conflicts of interest in this work.

\section{References}

1. Powell CA, Halmos B, Nana-Sinkam SP. Update in lung cancer and mesothelioma 2012. Am J Respir Crit Care Med. 2013;188:157-166.

2. Vestbo J, Hurd SS, Agusti AG, et al. Global strategy for the diagnosis, management, and prevention of chronic obstructive pulmonary disease: GOLD executive summary. Am J Respir Crit Care Med. 2013;187: 347-365.

3. Izquierdo JL, Resano P, El Hachem A, Graziani D, Almonacid C, Sánchez IM. Impact of COPD in patients with lung cancer and advanced disease treated with chemotherapy and/or tyrosine kinase inhibitors. Int J Chron Obstruct Pulmon Dis. 2014;9:1053-1058.

4. de Torres JP, Marin JM, Casanova C, et al. Lung cancer in patients with chronic obstructive pulmonary disease - incidence and predicting factors. Am J Respir Crit Care Med. 2011;184:913-919.

5. Young RP, Hopkins RJ, Christmas T, Black PN, Metcalf P, Gamble GD. COPD prevalence is increased in lung cancer, independent of age, sex and smoking history. Eur Respir J. 2009;34:380-386.

6. Zhai R, Yu X, Shafer A, Wain JC, Christiani DC. The impact of coexisting COPD on survival of patients with early-stage non-small cell lung cancer undergoing surgical resection. Chest. 2014;145:346-353.

7. Berry MF, Jeffrey Yang CF, Hartwig MG, et al. Impact of pulmonary function measurements on long-term survival after lobectomy for stage I non-small cell lung cancer. Ann Thorac Surg. 2015;100:271-276.

8. Detterbeck FC, Boffa DJ, Tanoue LT. The new lung cancer staging system. Chest. 2009;136:260-271.

9. Standardization of spirometry - 1987 update. Statement of the American Thoracic Society. Am Rev Respir Dis. 1987;136:1285-1298.

10. Disease GIfCOL. Global strategy for the diagnosis, management, and prevention of chronic obstructive pulmonary disease. Available from: http://www.goldcopd.org. Accessed September 5, 2015.

11. Martini N, Bains MS, Burt ME, et al. Incidence of local recurrence and second primary tumors in resected stage I lung cancer. $J$ Thorac Cardiovasc Surg. 1995;109:120-129.

12. Gomes M, Teixeira AL, Coelho A, Araújo A, Medeiros R. The role of inflammation in lung cancer. Adv Exp Med Biol. 2014;816:1-23.
13. Takiguchi $\mathrm{Y}$, Sekine I, Iwasawa $\mathrm{S}$, et al. Chronic obstructive pulmonary disease as a risk factor for lung cancer. World J Clin Oncol. 2014; 5:660-666.

14. King PT. Inflammation in chronic obstructive pulmonary disease and its role in cardiovascular disease and lung cancer. Clin Transl Med. 2015;4:68.

15. Mannino DM, Aguayo SM, Petty TL, Redd SC. Low lung function and incident lung cancer in the United States: data From the First National Health and Nutrition Examination Survey follow-up. Arch Intern Med. 2003;163:1475-1480.

16. van Gestel YR, Hoeks SE, Sin DD, et al. COPD and cancer mortality: the influence of statins. Thorax. 2009;64:963-967.

17. Buist AS, McBurnie MA, Vollmer WM, et al. International variation in the prevalence of COPD (the BOLD Study): a population-based prevalence study. Lancet. 2007;370:741-750.

18. Gullon JA, Suarez I, Medina A, et al. Role of emphysema and airway obstruction in prognosis of lung cancer. Lung Cancer. 2011;71: $182-185$.

19. Kiri VA, Soriano J, Visick G, et al. Recent trends in lung cancer and its association with COPD: an analysis using the UK GP Research Database. Prim Care Respir J. 2010;19:57-61.

20. Sekine Y, Yamada Y, Chiyo M, et al. Association of chronic obstructive pulmonary disease and tumor recurrence in patients with stage IA lung cancer after complete resection. Ann Thorac Surg. 2007;84:946-950.

21. Arca JA, Lamelas IP, Ortega RA, et al. Lung cancer and COPD: a common combination. Arch Bronconeumol (English Edition). 2009;45:502-507.

22. Lee SJ, Lee J, Park YS, et al. Impact of chronic obstructive pulmonary disease on the mortality of patients with non-small-cell lung cancer J Thorac Oncol. 2014;9:812-817.

23. Ueda K, Jinbo M, Li T-S, Yagi T, Suga K, Hamano K. Computed tomography-diagnosed emphysema, not airway obstruction, is associated with the prognostic outcome of early-stage lung cancer. Clin Cancer Res. 2006;12:6730-6736.

24. Mantovani A, Allavena P, Sica A, Balkwill F. Cancer-related inflammation. Nature. 2008;454:436-444.

25. Punturieri A, Szabo E, Croxton TL, Shapiro SD, Dubinett SM. Lung cancer and chronic obstructive pulmonary disease: needs and opportunities for integrated research. J Natl Cancer Inst. 2009;101:554-559.

26. Qian Q, Shi X, Lei Z, et al. Methylated $+58 \mathrm{CpG}$ site decreases DCN mRNA expression and enhances TGF-beta/Smad signaling in NSCLC cells with high metastatic potential. Int J Oncol. 2014;44:874-882.

27. Schwartz AG, Ruckdeschel JC. Familial lung cancer: genetic susceptibility and relationship to chronic obstructive pulmonary disease. Am J Respir Crit Care Med. 2006;173:16-22.
International Journal of COPD

\section{Publish your work in this journal}

The International Journal of COPD is an international, peer-reviewed journal of therapeutics and pharmacology focusing on concise rapid reporting of clinical studies and reviews in COPD. Special focus is given to the pathophysiological processes underlying the disease, intervention programs, patient focused education, and self management protocols.

\section{Dovepress}

This journal is indexed on PubMed Central, MedLine and CAS. The manuscript management system is completely online and includes a very quick and fair peer-review system, which is all easy to use. Visit http://www.dovepress.com/testimonials.php to read real quotes from published authors. 